\title{
The association between social support and physical activity in older adults: a systematic review
}

Gabrielle Lindsay Smith ${ }^{1 *}$, Lauren Banting ${ }^{1}$, Rochelle Eime ${ }^{1,2}$, Grant O'Sullivan ${ }^{1}$ and Jannique G. Z. van Uffelen ${ }^{1,3}$

\begin{abstract}
Background: The promotion of active and healthy ageing is becoming increasingly important as the population ages. Physical activity (PA) significantly reduces all-cause mortality and contributes to the prevention of many chronic illnesses. However, the proportion of people globally who are active enough to gain these health benefits is low and decreases with age. Social support (SS) is a social determinant of health that may improve PA in older adults, but the association has not been systematically reviewed.

This review had three aims: 1) Systematically review and summarise studies examining the association between SS, or loneliness, and PA in older adults; 2) clarify if specific types of SS are positively associated with PA; and 3) investigate whether the association between SS and PA differs between PA domains.

Methods: Quantitative studies examining a relationship between SS, or loneliness, and PA levels in healthy, older adults over 60 were identified using MEDLINE, PSYCInfo, SportDiscus, CINAHL and PubMed, and through reference lists of included studies. Quality of these studies was rated.

Results: This review included 27 papers, of which 22 were cross sectional studies, three were prospective/ longitudinal and two were intervention studies. Overall, the study quality was moderate. Four articles examined the relation of PA with general SS, 17 with SS specific to PA (SSPA), and six with loneliness. The results suggest that there is a positive association between SSPA and PA levels in older adults, especially when it comes from family members. No clear associations were identified between general SS, SSPA from friends, or loneliness and PA levels. When measured separately, leisure time PA (LTPA) was associated with SS in a greater percentage of studies than when a number of PA domains were measured together.
\end{abstract}

Conclusions: The evidence surrounding the relationship between SS, or loneliness, and PA in older adults suggests that people with greater SS for PA are more likely to do LTPA, especially when the SS comes from family members. However, high variability in measurement methods used to assess both SS and PA in included studies made it difficult to compare studies.

Keywords: Physical activity, Social support, Loneliness, Older adults/aging, Systematic review

\footnotetext{
* Correspondence: gabrielle.lindsaysmith@live.vu.edu.au

${ }^{1}$ Institute of Sport, Exercise and Active Living, Victoria University, Melbourne,

Australia

Full list of author information is available at the end of the article
}

(c) The Author(s). 2017 Open Access This article is distributed under the terms of the Creative Commons Attribution 4.0 International License (http://creativecommons.org/licenses/by/4.0/), which permits unrestricted use, distribution, and reproduction in any medium, provided you give appropriate credit to the original author(s) and the source, provide a link to the Creative Commons license, and indicate if changes were made. The Creative Commons Public Domain Dedication waiver (http://creativecommons.org/publicdomain/zero/1.0/) applies to the data made available in this article, unless otherwise stated. 


\section{Background}

The global population is ageing due to an increase in life expectancy and a reduction in fertility rates. In 2010, an estimated 524 million people were aged 65 or older $8 \%$ of the world's population. By 2050 this is expected to nearly triple to 1.5 billion, representing about $16 \%$ of the world's population [1]. It is well known that age is an independent risk factor for the development of noncommunicable diseases (NCDs) such as cardiovascular disease, cancer, diabetes and dementia [1]. Even without NCDs, function and independence generally decline in older age as a result of reductions in cognitive and physical capacity (e.g. muscle strength, balance, cardiovascular endurance) [2, 3]. Now more than ever it is vital to investigate ways to encourage aging well [4] or 'Active Ageing'. This phrase refers to older adults being enabled to continue participating in "social, economic, cultural, spiritual and civic affairs" and maintain a good quality of life [5]. Promotion of Active Ageing has the potential to slow the otherwise ever-growing burden on national economies and health care systems worldwide and more importantly, to ensure that older adults are able to enjoy their lives to the best of their capacities.

Performing sufficient physical activity (PA) is a primary modifiable determinant of health especially pertinent to Active Ageing because it is known to have vast mental and physical health benefits for people of all ages $[6,7]$. In adults, PA reduces the risk of all-cause mortality, prevents various chronic diseases, and in older adults especially, it reduces the risk of falls and helps maintain physical and cognitive function [8-17]. Despite the known benefits of regular PA [18], 23\% of adults globally are insufficiently active, with some high income countries having inactivity rates of up to 54\% [14]. Inactivity rates increase with age, with around two-thirds of those between 65-74 years and three-quarters of those over 75 years not meeting PA guidelines of at least $150 \mathrm{~min} /$ week of moderate intensity activity in either the US [15] or Australia [17].

In order to have a more active and healthy ageing population, it is vital to investigate ways to increase PA levels in older adults. Research addressing the most appropriate intervention methods is still inconclusive. However, many behaviour change theories, including the Social Cognitive Theory [19], Social-Ecological Model [20, 21], Theory of Planned Behaviour [22] and the Health Belief Model [23], highlight the importance of social factors such as social support (SS) and social connectedness in maintaining and/or initiating behaviour change. These theories have also been used in PA behaviour change research with older adults [24-29]. Furthermore, the World Health Organisation (WHO) identifies SS as a key determinant of Active Ageing [5], because of the importance of strong social ties for life satisfaction and subjective wellbeing in older adults. It is vital that social interactions are maintained with increasing age, as good social functioning is associated with improved self-efficacy [30-32], reduced risk of depression $[33,34]$ and a reduced risk of all-cause mortality [35]. Older adults have the potential to experience greater levels of loneliness and decreased SS as they encounter significant life events such as retirement, loved ones becoming unwell or passing away, or moving into care [36]. Furthermore, experiencing multiple life events at once is associated with a reduction in physical activity levels in this population group [37].

Despite having featured prominently in research for some time, SS is still a contentious and poorly defined concept, but with agreement that it is multifaceted [38-40]. A critical appraisal of the literature by Williams et al. [40] found 25 variations on the definition of SS in use. Key themes identified in the SS definitions were social relationships that are reciprocal, accessible and reliable and provide any or a combination of supportive resources (e.g. emotional) and distraction from stressors or information [40]. Additionally, the WHO defines SS as being both 'emotional and practical support characterising good social relations' and a social determinant of health [41]. In the description of SS by the WHO, there is also referral to an absence of loneliness [5]. Whilst social support and loneliness are not the opposite of one another and one can be lonely without being socially isolated, they have been shown to be directly linked in community-dwelling older adults [34] and thus we have included loneliness in this review.

In the general adult population there has been some suggestion that task-specific SS is more important than general support for maintaining or changing health behaviours [42, 43]. However, for PA behaviour this association does not seem to be as clear-cut, with studies supporting a positive association between PA and both general SS [44-46] and support specific to PA [47-49]. It is possible that similar associations also exist in older adults but these have not been summarised before, therefore this will be addressed in this review. There may also be value in understanding the specific role of different sources of SS (e.g. friends, family or exercise group) and PA levels in older adults. Kouvonen et al. [30] reported that people with high emotional support from their closest significant other, who met PA guidelines, were more likely to still be undertaking adequate PA five years later. Eyler et al. [49] found that high SS from both friends and family was significantly associated with greater PA levels in women. Not only the type and source of SS may play a role in the association between SS and PA, this association may also differ across the PA domains of active transport, active recreation or leisure 
time PA, household activities and occupational activities [50]. For example, studies synthesised in a recent systematic review of the association between SS and PA in adolescents consistently found a positive association between support from both parents and friends and leisure time PA, whereas the transport domain of PA was only consistently and positively associated with SS from friends [51].

As demonstrated above, the research surrounding SS and PA in adults is varied and therefore difficult to generalise to older adults with certainty. Also, in older adults the literature has not been reviewed and summarised in the past. Given the considerable societal changes occurring with the ageing population and the importance of PA to the health and quality of life in older adults, a review of the research evidence for this population group is warranted. Therefore this review has three aims: 1) systematically review and summarise the studies examining the association between SS, including loneliness as per the WHO definition, and PA in older adults; 2) clarify if any potential associations differ between types (e.g. task specific support, general support) or sources of support (e.g., support from family, friends or exercise group); and 3) investigate whether the association between SS and PA in older adults differs between specific $P A$ domains (LTPA, transport, household, occupational).

\section{Methods}

\section{Protocol}

The Preferred Reporting Items for Systematic Reviews and Meta-Analyses (PRISMA) checklist has been followed to undertake this systematic review [52].

\section{Study eligibility criteria}

Studies examining the association between social support, including loneliness, and physical activity (PA) in older adults and meeting the following criteria were included: 1) Generally healthy, community dwelling older adults with a mean age of at least 60 years, as per the definition of the UN [53] and a minimum age of no less than 50. If the mean age or age range of participants was not clear the paper was excluded; 2) A validated measure of SS with at least two items or a validated measure of loneliness; 3) PA was measured objectively or subjectively using measures with established validity as reported in the individual papers, or with clear face validity [54]. As Terwee et al. [54] state in their review of measurement characteristics of PA questionnaires, face validity is often the most important measurement property of a questionnaire and the relevance of other aspects of validation (e.g. reliability, validity, responsiveness) differs depending on what the scale intends to measure. Therefore, PA questionnaires with clear face validity were included in this review. In addition, PA data needed to be analysed appropriately, i.e. studies that analysed ordinal PA data as a continuous variable were excluded; and 4) Peer reviewed, quantitative studies, regardless of study design, available in English, German, French or Dutch were considered for inclusion.

\section{Information sources and search}

Systematic searches of MEDLINE, PSYCInfo, SportDiscus, CINAHL (via EBSCOHost Megafile premier) and PubMed were conducted in August 2014. No limit to dates of coverage was applied to these searches. Free terms as well as appropriate thesaurus terms of each database were combined for the population, SS, including loneliness, and PA. An example full search strategy for PubMed is included in a separate file (see Additional file 1). Full search strategies for EBSCOHost are available from the first author on request.

\section{Study selection}

Results of the database searches were imported into Endnote X7 and duplicates were removed. Titles and abstracts were then screened by one reviewer (GLS) to remove papers out of scope. Next, full texts were screened in detail by one reviewer (GLS) to check if the inclusion criteria were met. Two authors then independently reviewed the papers in the final list. Reference lists of included papers were screened to identify additional studies meeting the inclusion criteria. In case of any uncertainty during the review process, an additional reviewer was consulted and a consensus decision was made.

\section{Data extraction}

Data were extracted by two reviewers according to the following pre-agreed categories: Country where study was conducted, study design, sample size, participant characteristics (age [mean and range], gender), PA and SS or loneliness measures, results and adjustments in multivariate analyses. See Table 2 and Table 3 for further details. Authors were contacted for more information if there was insufficient detail about validation of the SS/ loneliness measure.

\section{Risk of bias and quality assessment}

The Gyorkos risk assessment tool was used to rate the quality of included papers, as it includes items to assess the quality of multiple study designs [55, 56]. All reviewers came to a consensus about the definitions of major and minor flaws for the various study designs as recommended in the rating instructions [56]. See Table 1 for details. In addition to overall study design, quality of SS (or loneliness) and PA variables were assessed for each study. For each study, every item was rated independently by 2 reviewers as 'yes', 'partially met,' 'no,' 'can't 
Table 1 Definitions of major and minor flaws for this SR

\begin{tabular}{|c|c|c|c|}
\hline & $\begin{array}{l}\text { Experimental studies } \\
\text { (clinical trial or community trial) }\end{array}$ & $\begin{array}{l}\text { Longitudinal Observation } \\
\text { (cohort study or observational study) }\end{array}$ & Cross-sectional \\
\hline $\begin{array}{l}\text { Study population: } \\
\text { Major }\end{array}$ & $\begin{array}{l}\text { - No Control } \\
\text { - Sample size inadequate for power } \\
(n<20 \text { per group) } \\
\text { - Non-random allocation or } \\
\text { randomisation not described }\end{array}$ & $\begin{array}{l}\text { - Not representative of the population } \\
\text { of interest. In relation to age, gender } \\
\text { AND } \\
\text { - Confounders not accounted for } \\
\text { - No description of sample }\end{array}$ & $\begin{array}{l}\text { - Not representative of the population } \\
\text { of interest. In relation to age, gender } \\
\text { AND } \\
\text { - Confounders not accounted for. } \\
\text { - No description of sample }\end{array}$ \\
\hline Minor & $\begin{array}{l}\text { - Confounders not completely } \\
\text { accounted for } \\
\text { - Omission of detail about confounders. }\end{array}$ & $\begin{array}{l}\text { - Not representative of the population } \\
\text { of interest. In relation to age, gender } \\
\text { - Omission of detail about confounders } \\
\text { - Non-random sampling } \\
\text { - Sample size inadequate for power } \\
\text { ( } n<10 \text { per variable) or not described } \\
\text { (if study } n<500 \text { ) }\end{array}$ & $\begin{array}{l}\text { - Not representative of the population } \\
\text { of interest. In relation to age, gender } \\
\text { - Confounders not accounted for } \\
\text { - Non-random sampling } \\
\text { - Sample size inadequate for power } \\
\text { ( } n<10 \text { per variable) or not described } \\
\text { (if study } n<500)\end{array}$ \\
\hline $\begin{array}{l}\text { Intervention/ exposure: } \\
\text { Major }\end{array}$ & $\begin{array}{l}\text { - No description of the PA or SS component } \\
\text { of the intervention } \\
\text { - No measurement of intervention } \\
\text { strength or exposure } \\
\text { - Intervention }<12 \text { weeks }\end{array}$ & $\begin{array}{l}\text { - No measurement of exposure } \\
\text { - Poor or no face validity of } \\
\text { measurement of exposure }\end{array}$ & $\begin{array}{l}\text { - No measurement of exposure } \\
\text { - Poor or no face validity of } \\
\text { measurement of exposure }\end{array}$ \\
\hline Minor & - No blinding & $\begin{array}{l}\text { - No validity of measurement PA } \\
\text { or SS exposure mentioned }\end{array}$ & $\begin{array}{l}\text { - No validity of measurement } \\
\text { PA or SS exposure mentioned }\end{array}$ \\
\hline $\begin{array}{l}\text { Outcome: } \\
\text { Major }\end{array}$ & $\begin{array}{l}\text { - Poor face validity of measurement } \\
\text { of outcome }\end{array}$ & $\begin{array}{l}\cdot \text { Poor or no face validity of } \\
\text { measurement of exposure }\end{array}$ & $\begin{array}{l}\text { - Poor or no face validity of } \\
\text { measurement of PA or } \\
\text { SS outcome }\end{array}$ \\
\hline Minor & $\begin{array}{l}\text { - No validity of PA or SS outcome } \\
\text { measure mentioned }\end{array}$ & $\begin{array}{l}\text { - No validity of PA or SS outcome } \\
\text { measure mentioned }\end{array}$ & $\begin{array}{l}\text { - No validity of PA or SS } \\
\text { outcome measure mentioned }\end{array}$ \\
\hline $\begin{array}{l}\text { Follow-up: } \\
\text { Major }\end{array}$ & $\begin{array}{l}\text { - High drop-out ( }>20 \% \text { ) (from pre to } \\
\text { post- test measurement) }\end{array}$ & $\begin{array}{l}\cdot \text { High drop-out (>20\%) (from } \\
\text { pre to post-test measurement) }\end{array}$ & $\cdot N A$ \\
\hline Minor & $\begin{array}{l}\text { - High drop out in long term follow } \\
\text { up (post intervention) } \\
\text { - No long term follow up }\end{array}$ & $\begin{array}{l}\text { - High drop out in long term } \\
\text { follow up (post intervention) } \\
\text { - No long term follow up }\end{array}$ & •NA \\
\hline
\end{tabular}

tell' or 'NA'. Based on these ratings the overall quality was rated by each reviewer as:

Strong: No major flaws, a few minor flaws - any plausible postulated bias was unlikely to seriously alter the results,

Moderate: No major flaws, some minor flaws - a plausible bias exists that brought into question the confidence that could be attached to the results,

Weak: One or more major flaws - a plausible bias existed that seriously weakened confidence in the results.

In case of discrepancies between reviewers in the final quality rating, a third reviewer assessed the study and the three reviewers discussed to resolve the disagreement.

\section{Data synthesis}

The studies were categorised as focusing on loneliness, general SS or SS specific to PA. Each paper was rated as + or - if a statistically significant positive or negative association was found; 0 was assigned if no statistically significant association was found (In the remainder of this paper, 'statistically significant' results will be referred to as 'significant'). Studies reporting differences in results for males and females, or in the type, source and/or domain or PA are coded multiple times (See Table 3 for details of quality assessment). To summarize the associations found in the studies, the following overall ratings, as suggested by Sallis et al. [57], were given to each section: "0" (No association; $0 \%-33 \%$ of the findings supported the association), "?” (indeterminate association; 34-59\% of the findings supported the positive or negative association), "+" or "- "(positive or negative association; 60\%-100\% of the findings supported the association) [57] (see Table 4 for overall quality ratings for each category).

\section{Results}

Study selection

Of the 4265 papers identified in the search, 3349 remained after removing duplicates. After screening titles and abstracts to remove papers out of scope, the full text of 211 papers was checked. Of these, 24 met the inclusion criteria. Three further relevant studies were identified in backward reference tracking giving a total of 27 papers for the review (See Fig. 1). 


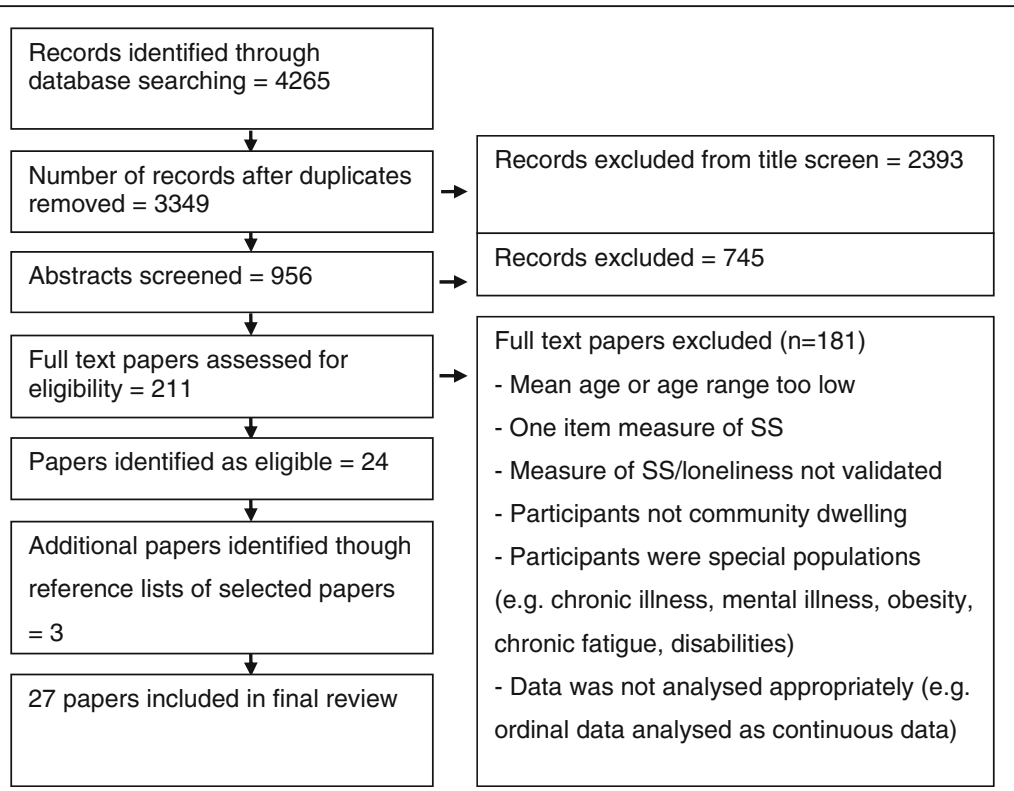

Fig. 1 Search process flow chart

\section{General study characteristics}

More than three quarters of the included studies (21 studies) examined the association between SS and PA, and the remaining six studies investigated the relationship between loneliness and PA levels [58-63]. Of the studies examining the association between SS and PA, 17(81\%) examined the association between SS specific to PA or exercise [31, 64-79] and the remaining four examined the association between general SS and PA [80-83].

The majority of the studies (67\%) were published between 2006 and 2014 with the oldest paper published in 1992 [83]. Seventeen studies were conducted in either the USA or Canada, with six from Asia, two from Europe [61, 66], one from Australia [64] and one from Israel [59]. More than $80 \%$ of the identified studies (22 studies) were cross-sectional, three were longitudinal $[58,60,71]$ and two were experimental $[66,79]$ (see Table 2). Sample sizes ranged from 64 [79] to 13,812 [63]. Most studies incorporated both males and females and four included females only $[67,72,78,65]$. Only four studies assessed sex differences relating to SS and PA levels [59, 70, 73, 80]. See Table 2 for details.

\section{Quality rating}

The quality of the four studies examining the association between general SS and PA levels was moderate for three studies [80, 81, 83] and weak for one study [82]. Ten of the 17 papers examining the association between PA specific SS and PA levels were of moderate quality and the other seven were of weak quality.
Of the six studies examining the association between loneliness and PA, all were of moderate quality, except for the longitudinal study by Newall et al. [60], which was of weak quality. For further details see Table 2.

\section{Measurement and analysis of social support and physical activity}

The way PA was measured and analysed varied widely between studies. Overall, 23 of the studies used self-report PA measures and four used objective PA measures. The majority (74\%) of studies collected continuous PA data and the remaining seven collected categorical (ordinal) data. Seven of the papers transformed the data into categories such as active or inactive based on pre-defined cut-offs for analysis purposes. Further details about collection and analysis of the PA measures in each of the three categories (i.e. general SS, SS for PA, loneliness) is described in Table 2 and Additional file 2. There were also a wide range of social support and loneliness scales used in the studies in this review. The SSPA category of studies had the most consistency of scales, with 14 out of 17 utilising various versions of The Sallis SS for Leisure Scale [42]. See Table 2 for more detail of scales used in the included studies and Additional file 2 for more detail.

\section{Relationship between SS, loneliness and PA}

Overall, of the 21 studies examining the association between either general or PA specific SS and PA levels, 13 found a significant positive association and one study found a significant negative association [75]. Four of the six loneliness studies $[58,59,61,63]$ found a significant negative association. 


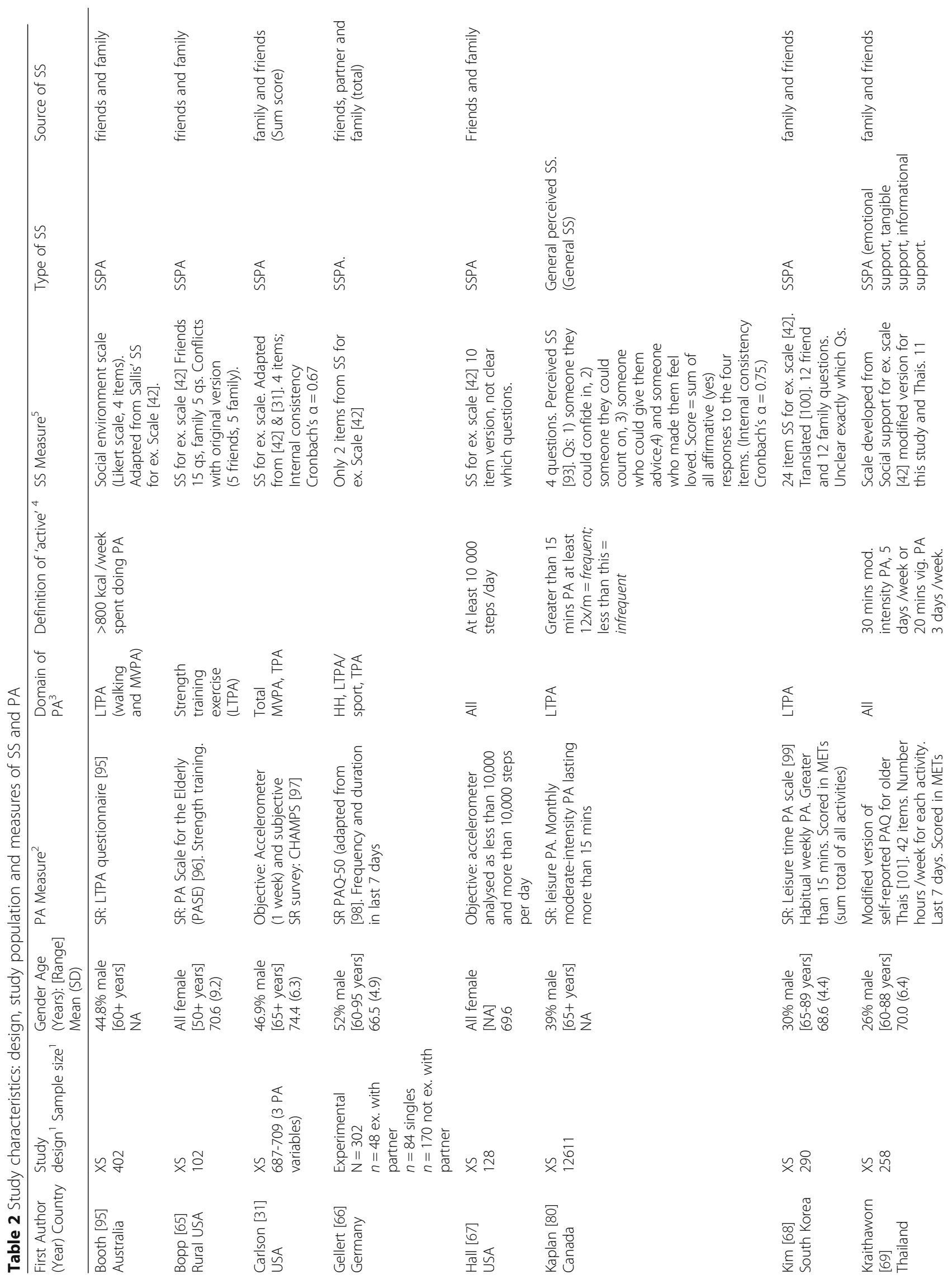




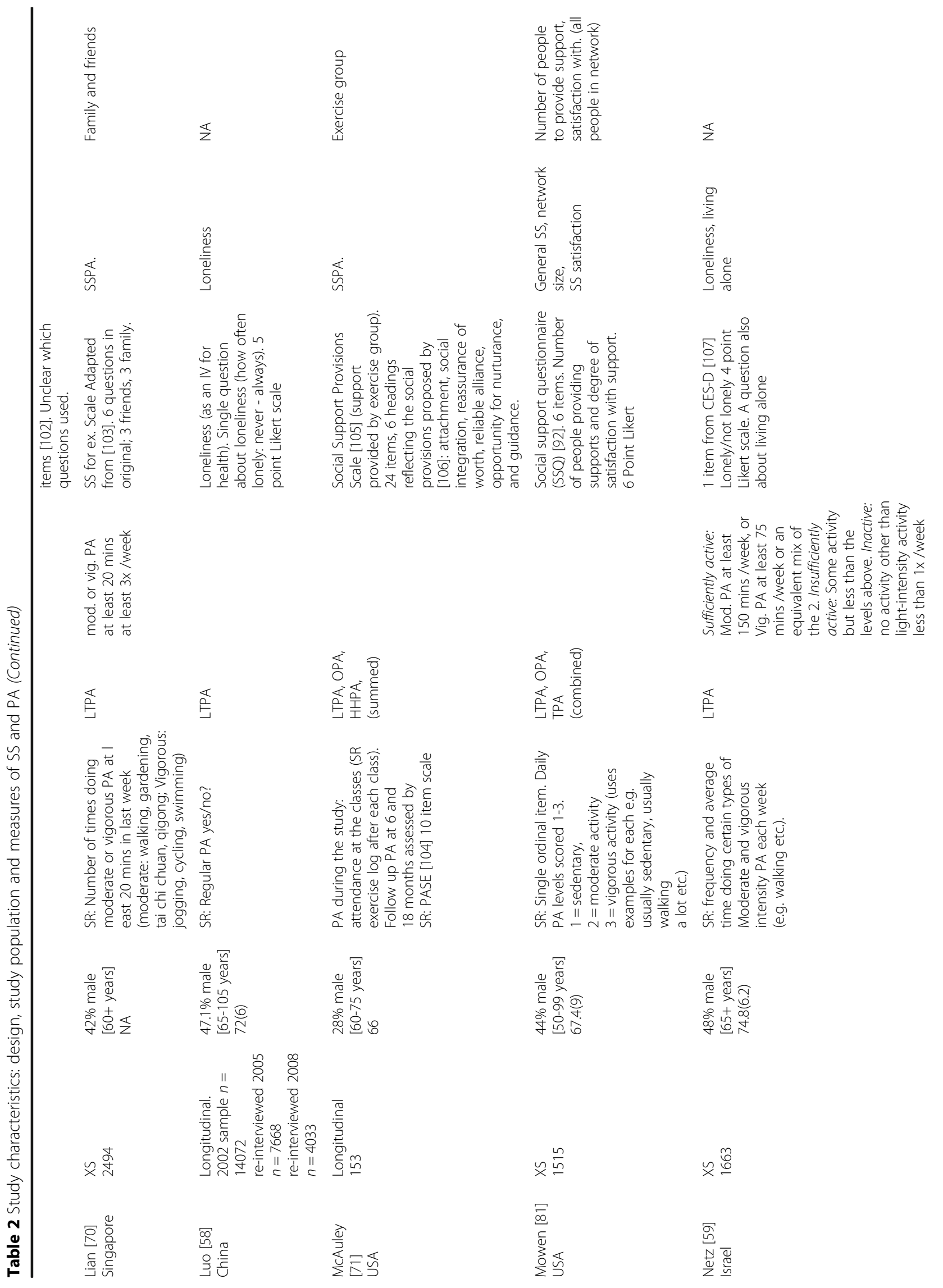




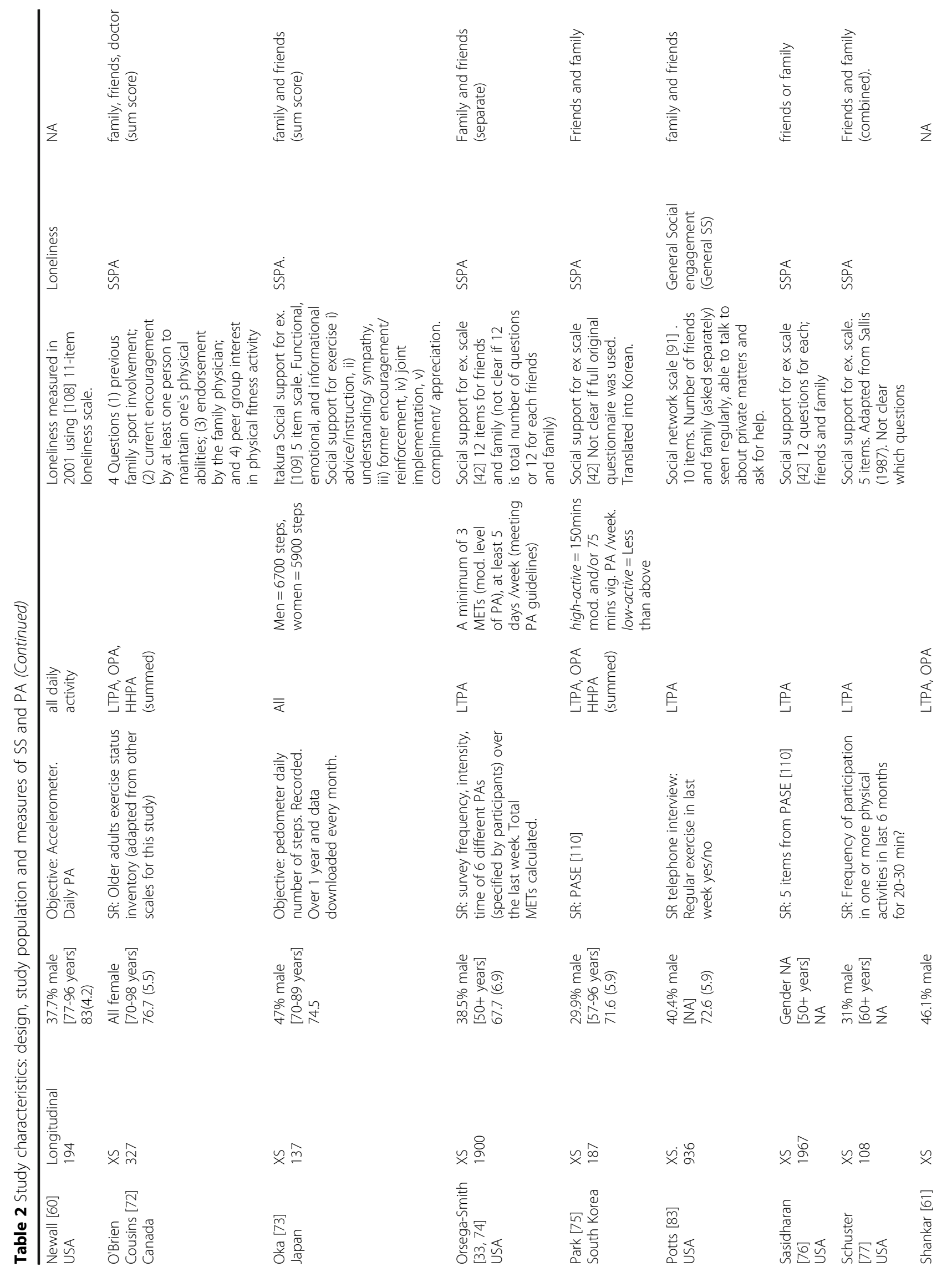




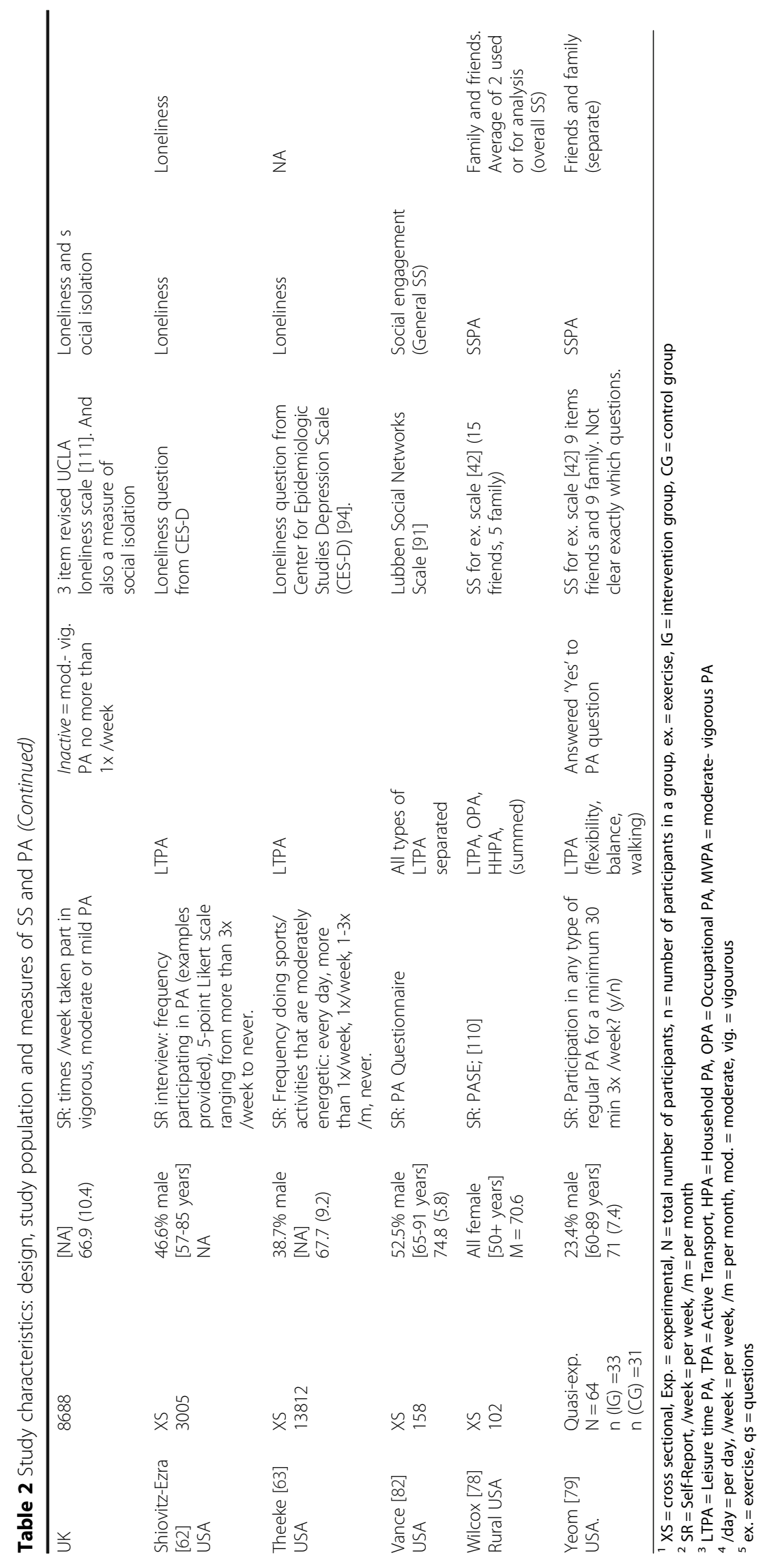


In the four female only studies, one found a significant association for SSPA overall [72] and one found an association for SSPA from family only [65]. In the four studies stratified for gender, two found an association for females only. One was for general SS [80] and the other was for loneliness [59]. Of the remaining two studies, which both focused on SSPA, one found a positive association for SSPA from family but not friends in both males and females [70]. See below for further details within each of the three categories.

\section{General social support and physical activity levels}

Five associations were reported in the four studies examining the association between generalised SS or social engagement and PA levels. Only two of these (40\%) were positive and significant (greater SS being associated with greater likelihood of doing PA); one for both genders [83] and one for females only [80]. This suggests an overall unclear association between general SS and PA levels when using pre-defined cut-offs established by Sallis [57]. See Table 4 for details.

\section{Social support specific to PA}

Of these 17 studies, 11 described at least one significant positive association between SS for PA and PA levels. Of the eight studies where source of support was not delineated, five associations (63\%) were found to be positive and significant. This suggests an overall positive association between PA levels and SSPA from all sources [57]. In the eight studies where the association between PA levels and SS from friends or family were examined separately, four $(50 \%)$ reported a positive association for SSPA from friends $[68,74,76,79]$ and five (63\%) found a positive association for SSPA from family. One study found a negative association between SS from family and PA [75]. The one study examining SSPA from an exercise group did not find any direct association between SSPA and PA levels [71]. These results suggest an overall positive association between PA levels and SSPA from family but not from friends [57]. See Table 4 for details. When low quality studies were removed from the synthesis, the trend above was further supported, with four of the five $(80 \%)$ relevant moderate quality studies finding a positive association between SSPA from family members $[65,68,74,79]$ and an indeterminate overall association between PA levels and SSPA from friends. For more detail of these results, see Tables 3 and 4 .

\section{Loneliness and PA levels}

Seven associations were examined in the six papers focusing on the association between loneliness and PA. Four $(57 \%)$ of these were significant and negative $[58,59$, $61,63]$, indicating unclear support for the association between loneliness and PA levels [57]. When the one low quality study [60] was removed from the synthesis, the results suggest an overall negative association with $67 \%$ being significant and negative. See Tables 3 and 4 for details

\section{Association between SS, loneliness and specific PA domains}

Only LTPA and transport domains were assessed separately in the studies reviewed. LTPA was assessed in 15 studies and transport in one [31]. The other studies either assessed all, or a combination of several PA domains together. When placed into the three categories, the following overall trends were seen for LTPA: Three general SS studies examined LTPA [80, 82, 83]. One found a significant positive association between LTPA and SS, and one supported a significant positive association in females only [80]. This suggests an overall positive association between general SS and LTPA for females but not males [57]. Eight of the 17 SSPA studies assessed the LTPA domain. Two of these assessed SS from friends and family combined and both found significant positive associations, suggesting an overall positive association between LTPA and all sources of SS [57]. In the six studies that assessed the association between different sources of SS and LTPA, 67\% of results supported a significant positive association for friends and $83 \%$ for family. This indicates an overall positive association between LTPA levels and SSPA from both friends and family [57]. Four loneliness studies examined LTPA $[58,59,62,63]$. Within these, the results support an overall negative association between LTPA and loneliness for females only, with three of four associations $[58,59,63]$ being negative and significant in females but only two of four in males $[58,63]$. See Table 3 for more details. In the one study where transport PA was assessed separately, a positive association with SSPA was found [31].

\section{Discussion}

The aims of this review were to summarise the results of quantitative studies assessing whether SS or loneliness is associated with physical activity levels in older adults. Specifically, we investigated whether any potential associations differ between types (e.g. task specific support, general support) or sources of support (family or friends or exercise group); and whether any associations between SS and PA are specific to certain PA domains (e.g. LTPA, transport, household, occupational). SS is an important determinant of health, especially in older adults, as there are many important life events such as retirement, illness, and death causing SS to change in later life. Understanding how SS and loneliness are associated with PA in this population group may assist in development of more effective, targeted PA 


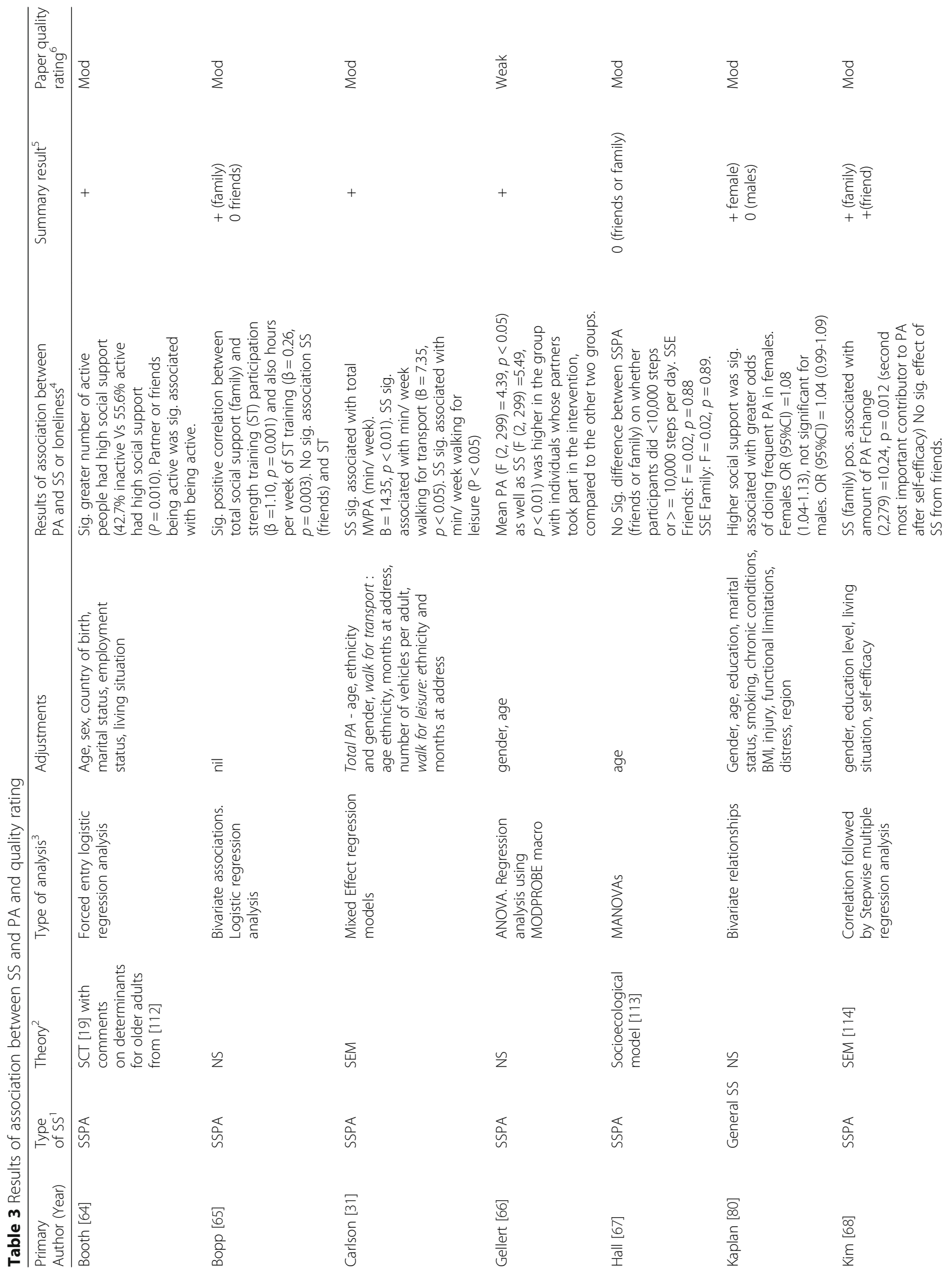




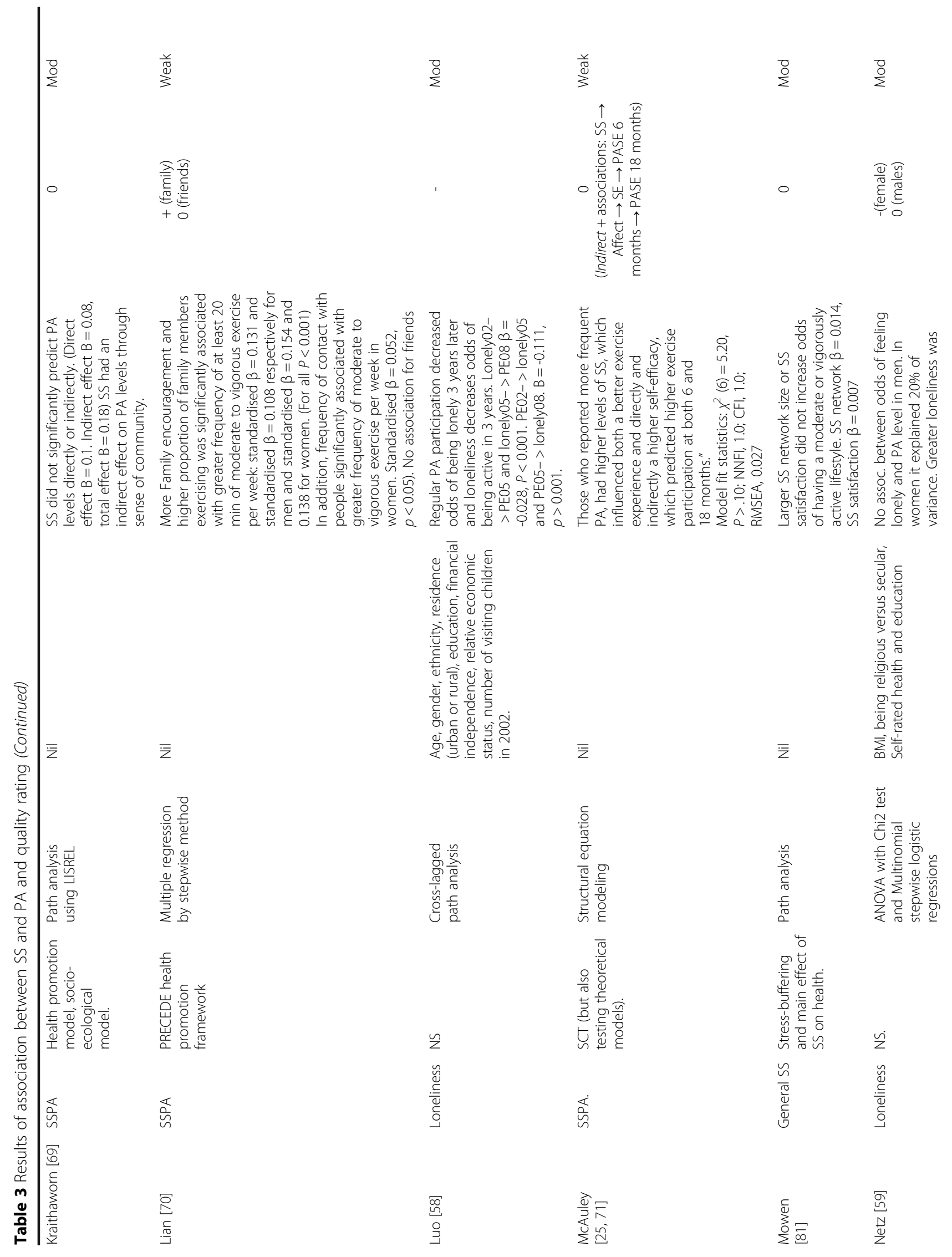




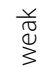

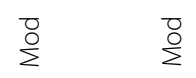

$\stackrel{0}{\Sigma}$

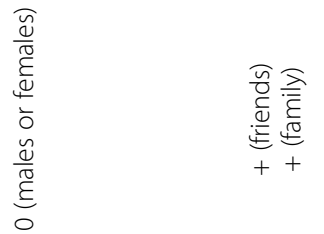

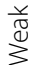

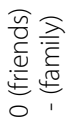

$\stackrel{\circ}{\Sigma}$

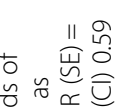

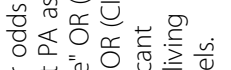

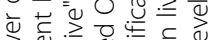

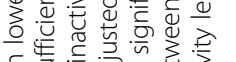

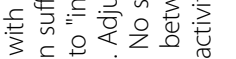

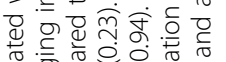

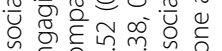
岗

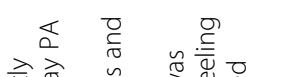

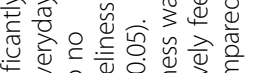

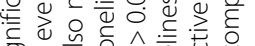

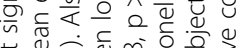

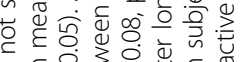

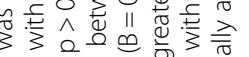

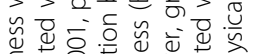

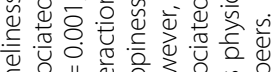

든

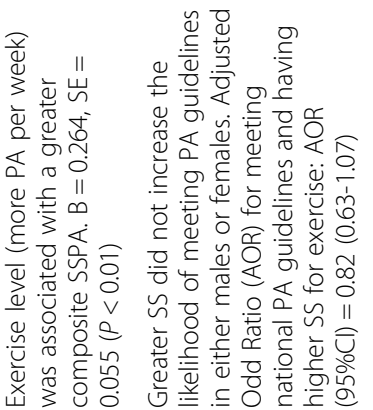

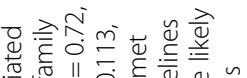
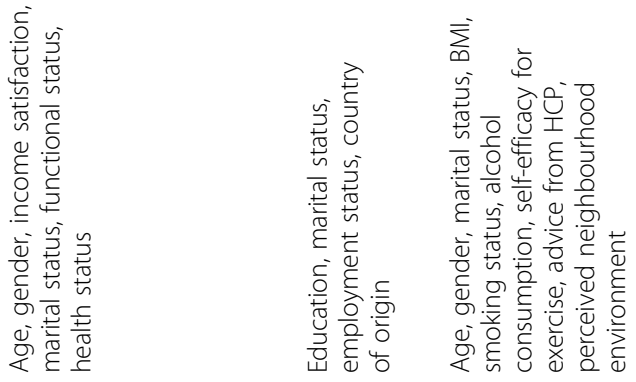

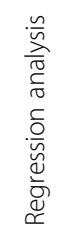
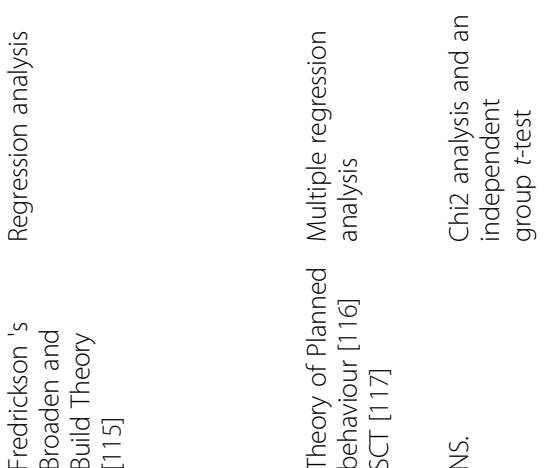

을
$\stackrel{\frac{1}{c}}{0}$
$\frac{0}{2}=$

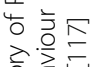

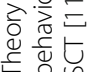

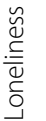

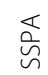

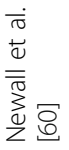

政

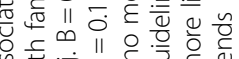

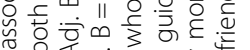

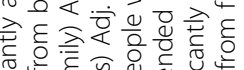

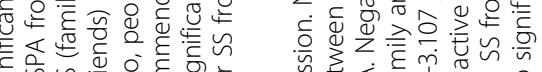

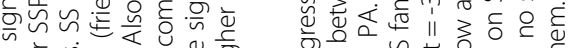

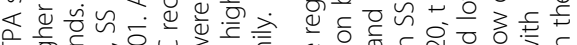

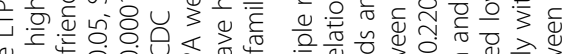

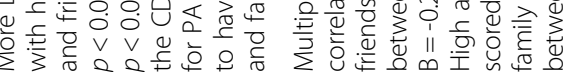

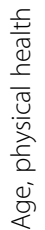

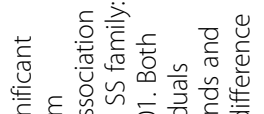

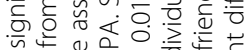

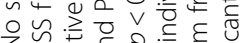
$z \backsim$ 苋

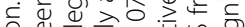

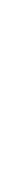

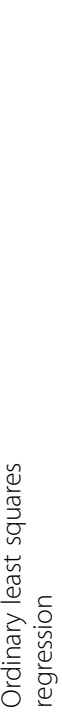

$\overline{\bar{z}}$

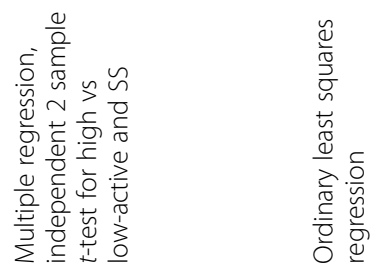

乏

$\begin{array}{ll}\frac{\pi}{n} & \frac{\pi}{n} \\ \frac{n}{n} & \end{array}$

$\frac{\approx}{\frac{\pi}{0}}$

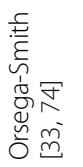

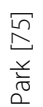

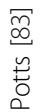




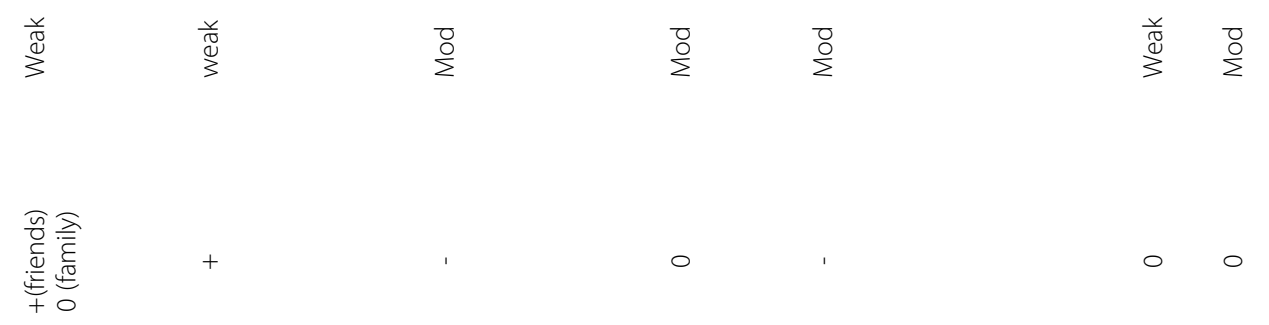

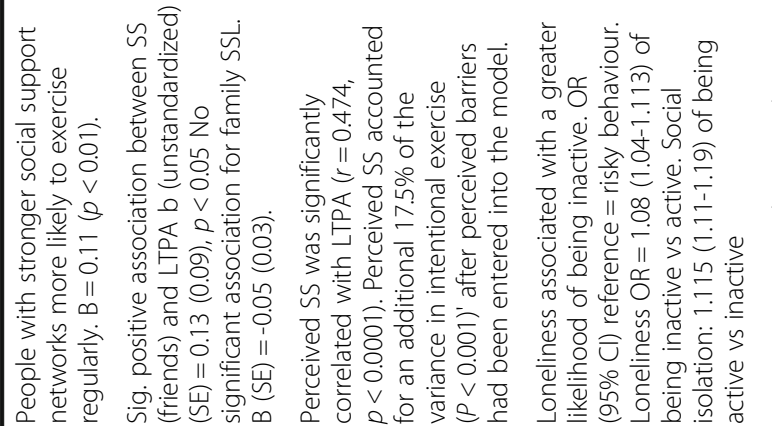

竞

宛

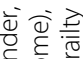

离过它

辛

芒脑

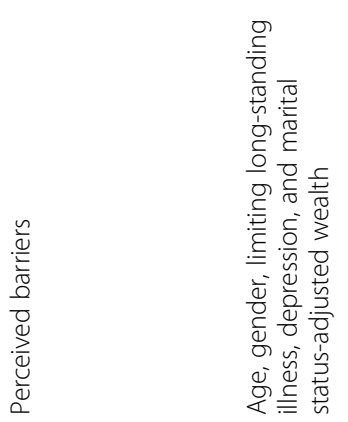

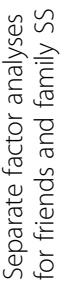
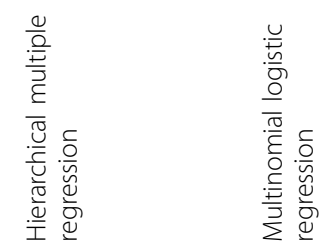

言宗

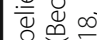

들 $\frac{0}{0}$

产市京

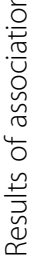

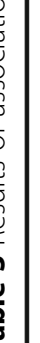

ঢ

$\frac{\overleftarrow{a}}{\sqrt[n]{n}}$

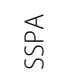

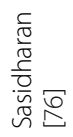

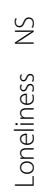

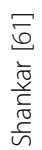

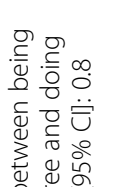

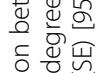

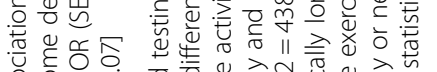

员话过

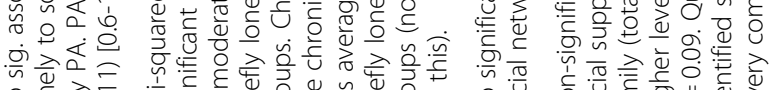
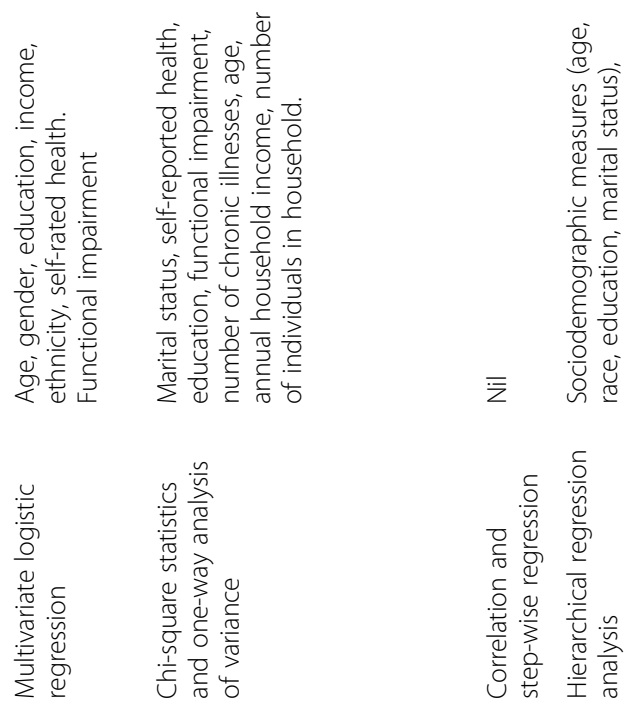


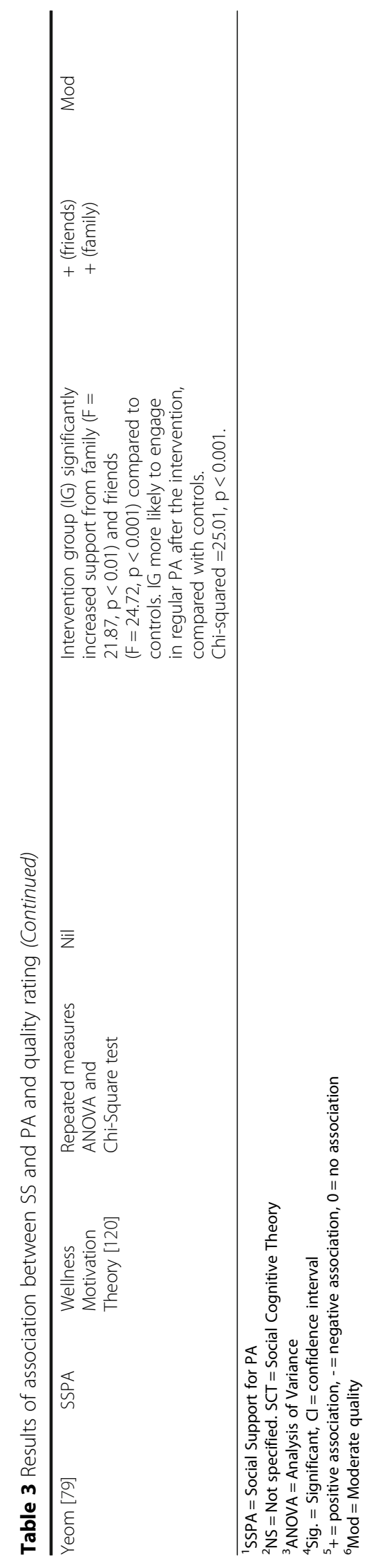


Table 4 Data synthesis - summary of results

\begin{tabular}{|c|c|c|c|c|c|c|c|}
\hline \multirow{3}{*}{$\begin{array}{c}\text { SS/ } \\
\text { loneliness } \\
\text { SS general }\end{array}$} & Assoc. & \multicolumn{5}{|c|}{ Studies (primary Author, Publication year) } & Summary \\
\hline & No & Mowen, 2007 & $\begin{array}{l}\text { Kaplan, } 2001 \\
\text { (males) }\end{array}$ & $\begin{array}{l}\text { Vance, } 2008 \text { (social } \\
\text { engagement) }\end{array}$ & & & \multirow[b]{2}{*}{ ? } \\
\hline & Positive & $\begin{array}{l}\text { Kaplan, } 2001 \\
\text { (females) }\end{array}$ & $\begin{array}{l}\text { Potts, } 1992 \\
\text { (social } \\
\text { engagement) }\end{array}$ & & & & \\
\hline \multirow[t]{2}{*}{$\begin{array}{l}\text { SSPA Sum } \\
\text { total }\end{array}$} & No & $\begin{array}{l}\text { Oka, } 2012 \\
\text { (males or } \\
\text { females) }\end{array}$ & $\begin{array}{l}\text { Kraithaworn, } \\
2011\end{array}$ & $\begin{array}{l}\text { Wilcox, 2003. RURAL } \\
\text { FEMALE STUDY }\end{array}$ & & & \multirow[b]{2}{*}{+} \\
\hline & Positive & Carlson, 2012 & Booth, 2000. & $\begin{array}{l}\text { O'Brien Cousins, } 1995 . \\
\text { FEMALE STUDY }\end{array}$ & Schuster, 1995 & $\begin{array}{l}\text { Gellert 2011; PA } \\
\text { and SS higher in } \\
\text { exercising spouse } \\
\text { group }\end{array}$ & \\
\hline \multirow[t]{2}{*}{$\begin{array}{l}\text { SSPA } \\
\text { friends }\end{array}$} & No & $\begin{array}{l}\text { Hall, } 2010 . \\
\text { FEMALE STUDY }\end{array}$ & $\begin{array}{l}\text { Bopp, } 2004 . \\
\text { Strength } \\
\text { training. } \\
\text { FEMALE } \\
\text { STUDY }\end{array}$ & Park, 2014. & $\begin{array}{l}\text { Lian, 1999. (males or } \\
\text { females) }\end{array}$ & & \multirow[t]{2}{*}{$?$} \\
\hline & Positive & Yeom, 2014. & $\begin{array}{l}\text { Orsega-Smith, } \\
2007 \text {. }\end{array}$ & Kim, 2013 & Sadisdharan, 2006 & & \\
\hline \multirow[t]{3}{*}{$\begin{array}{l}\text { SSPA } \\
\text { family }\end{array}$} & No & $\begin{array}{l}\text { Hall, } 2010 . \\
\text { FEMALE STUDY }\end{array}$ & $\begin{array}{l}\text { Sadisdharan, } \\
2006\end{array}$ & & & & \multirow{3}{*}{+} \\
\hline & Positive & Yeom, 2014 & $\begin{array}{l}\text { Orsega-Smith, } \\
2007 \text {. }\end{array}$ & Kim, 2013. & $\begin{array}{l}\text { Lian, } 1999 \text { (males } \\
\text { and females) }\end{array}$ & $\begin{array}{l}\text { Bopp, } 2004 . \\
\text { Strength training. } \\
\text { FEMALE STUDY }\end{array}$ & \\
\hline & Negative & Park, 2014 & & & & & \\
\hline $\begin{array}{l}\text { SSPA } \\
\text { exercise } \\
\text { group }\end{array}$ & No & $\begin{array}{l}\text { McAuley, } 2003, \\
6 \text { or } 18 \text { mo FU }\end{array}$ & & & & & \\
\hline \multirow[t]{2}{*}{ Loneliness } & No & $\begin{array}{l}\text { Shiovitz-Ezra, } \\
2014\end{array}$ & $\begin{array}{l}\text { Netz, } 2013 \\
\text { (males) }\end{array}$ & Newall. 2013 & & & \multirow[t]{2}{*}{$?$} \\
\hline & Negative & Luo, 2014. & Theeke, 2010. & Shankar. 2011. & Netz, 2013 (females) & & \\
\hline
\end{tabular}

Key

\begin{tabular}{|c|c|c|c|c|}
\hline $\begin{array}{c}\text { SS/ } \\
\text { Ioneliness }\end{array}$ & Assoc. & \multicolumn{2}{|c|}{ Studies (primary Author, Publication year) } & $\begin{array}{c}\text { Summary } \\
\text { score }\end{array}$ \\
\hline & & $\begin{array}{l}\text { Experimental } \\
\text { study }\end{array}$ & High quality & \\
\hline & & Longitudinal & $\begin{array}{l}\text { Moderate } \\
\text { quality }\end{array}$ & \\
\hline & & Cross sectional & Low quality & \\
\hline
\end{tabular}

1. $0=$ No association (0\%-33\% of the findings supported the association), ?= indeterminate association (34-59\% of the findings supported the positive or negative association), + = positive association, - = negative association; (60\%-100\% of the findings supported the association) [57]

interventions. This is the first review summarising the evidence in older adults.

\section{Relationship between different types and sources of social support, loneliness and physical activity}

Because of the differences in study designs and measurement of PA and SS, it was difficult to come to a clear consensus about differences in associations between types of SS and PA. However, the following advisory assessments can be made of associations between SS, loneliness and PA in older adults. There is moderate support that higher SS specific to PA from all sources combined, and from family specifically, is associated with higher levels of PA or meeting PA guidelines. This implies that older individuals with greater support to undertake PA, specifically from their family, will be more likely to be physically active in general. An unclear association was seen for SSPA from friends and PA levels but this relationship was clarified when leisure PA was examined alone (see results below). No clear overall association was supported for general support or loneliness, but after excluding the low quality studies from synthesis, moderate quality studies did suggest a significant negative association between loneliness and PA levels, indicating that people who were more lonely had lower PA levels. Given that there were far fewer studies in these two categories, further research would be warranted to confirm these above suggestions.

\section{Association between SS, loneliness and specific PA domains}

LTPA was the only domain examined in multiple studies. When these studies were synthesised, general SS in females and SSPA from friends and family were 
consistently positively associated with LTPA, rather than just family, as was evident with all studies combined. LTPA was also consistently negatively associated with loneliness in females. These findings are in line with those of a systematic review in adolescents, where more consistent positive associations were found between SS from all sources and LTPA levels than when PA domains were not separated [51]. The authors of the above review noted that questions in the SSPA scales focused on provision of SS for leisure and sport PA, which may explain why there were less consistent associations when other domains of PA were included in the analysis. The same is likely to be true for the Sallis SSPA scale used in many of the papers in this study, as all the questions are focused around exercising specifically [42]. Older adults are unlikely to associate other domains of PA (e.g. household or transport) as forms of 'exercise' and thus are likely to exclude this PA when considering the questions in the scale. Additionally, there is a difference between leisure activities and other types of physical activity (such as house work, transport or employment) in that they are done for solely enjoyment rather than function [84]. Social interaction and enjoyment have been described as two key reasons for participating in sport or (leisure) physical activity in both children and adults [85]. In adults, emotional support from others has been found to be positively associated with intrinsic motivation for PA ("behaviour engaged for pleasure and enjoyment"; p37 [47]) and in turn, participation in moderate to vigorous PA and walking. This suggests that greater emotional support from others encourages greater enjoyment in physical activity, which in turn makes people feel more motivated to do leisure exercise [47]. It is, however, less likely that greater support will likely have any impact on transport, occupational or household PA. To further explore potential differences between SS and different PA domains, future studies would benefit from using more detailed PA measures (either accelerometers or detailed scales) and ensuring domain specific PA is assessed as well as total PA.

\section{Other general findings of the review}

There were some gender differences highlighted in this review. Of the four studies that stratified by gender, there was some suggestion that the PA levels of women are more likely than men to be influenced by general SS [80] or loneliness [59], but not by SSPA [35, 70]. Social support has been positively associated with self-rated health in older women but not men in a number of studies [86, 87]. Sex differences could exist in the association between SS or loneliness and PA as well, as PA is a health-related variable. Given the small number of studies exploring this association and the sex differences in the typical ageing process, with women more likely to live longer with more health conditions than men [1], this warrants further investigation.

Most studies in this review used a very generic definition for older adults, for example everyone aged 60+ years, and did not stratify by age in the analysis. However, in reality, there are great differences in life circumstances between people who are defined as young old, mid-old and older old. Social factors like social support may influence PA levels differently amongst those in different age groups, with different health statuses, and in response to different life events. For example, a longitudinal study of women found that the death of a spouse was associated with increased PA in women aged 55-60 years but the same event had no impact on the PA levels of women aged 70+ years [88]. Although the age range of people who retire is broadening, the typical retirement age is 65 years and retirement is therefore more likely to be associated with PA in people in their midsixties than other age groups. Retirement has indeed been positively associated with PA levels in middle aged women [88]. Therefore, further associations may have been seen in some studies if they had been stratified by age or life stage. It may be worthwhile for researchers to consider doing this in future studies to examine if the association differs between subgroups of 'older people'.

All studies in this review were rated as weak to moderate for their measures of the key variables SS and PA (see Table 1). Part of the reason for the low quality rating of the PA measures in particular was that a decision was made by the authors to include papers with adequate face validity of these measures. This was decided because the aim of this review was to provide an overview of the association between SS and PA in a variety of studies; individualised, detailed assessments of questionnaire quality were outside its' scope. Face validity was deemed an appropriate measure of validity, as it is important and relevant for all study designs and purpose [54]. The use of validated PA measures was included in the quality rating procedure and therefore studies without validated PA measures were rated as low quality. Less than half the studies used externally validated PA scales or objective PA measures. This was probably because the majority of these studies did not specifically aim to examine the association between SS and PA. Thus, these constructs were often measured as part of a large test battery, which included brief measures of PA rather than more extensive validated questionnaires or objective measurements. However, the sample sizes of these studies were all greater than 900, and in large studies these more generalised questions amongst large test batteries are more acceptable [89].

\section{Study limitations and strengths}

This systematic review has several limitations. Firstly, there are limitations with regards to the inclusion of 
studies. Studies in older adults with specific medical conditions, such as obesity, cancer, heart conditions or other chronic illnesses, mental illness or disabilities were not included. This is likely to have excluded a number of potentially relevant studies because many older adults do have chronic illnesses and much research has been conducted with clinical populations. However, these studies were excluded due to the likelihood that SS relevant to clinical populations may differ to that more prevalent in the general population. In addition, qualitative studies, which can often offer more insight into a topic, were not included in this review to make comparison of studies more direct.

The variability of outcome measures used for assessing PA and SS or loneliness also made comparison of study results difficult. Specifically, there was almost no crossover between the types of SS scales used in the general SS studies, with only two of these SS studies using the same SS scale, the Lubben Social Network Scale [82, 83]. Scales measured one or a combination of the following: perception of support available, number of people available to provide support and satisfaction with support, indicating different components of SS that may have different associations with PA. There was also inconsistency in the measurement of SS for PA, with only one study [78] using the original scale developed by Sallis et al. [42] and 13 others using various versions of it. The original validation study had been conducted in people under the age of 45 [42], thus it may not be appropriate to measure SSPA in older people. The remaining three SSPA studies used different SSPA measures altogether [71-73]. Therefore, it is difficult to compare these studies conclusively. However, these SS measures do share some similar items such as family and/or friends offering verbal encouragement to do PA, or exercising together. The loneliness studies had much more overlap in loneliness measures, with three studies using the CES-D one item scale, assessing how often people felt lonely in the past week, and two of the other studies used scales with similar wording $[58,61]$. While there were differences in the scales used, there was greater agreement in the way SSPA and loneliness were assessed, than for general SS. This implies that the overall findings for the associations between SSPA and loneliness and PA are more reliable, but the general SS measures varied too much to have a strong sense of the overall association.

Despite the above limitations, inclusion of different study designs and studies with a variety of PA measures in the review has provided a detailed overview of current knowledge about SS and PA in older adults. Use of a quality rating scale suitable for different designs has allowed the authors to differentiate studies of differing quality and make stronger assumptions about the overall association between SS and PA. Use of the quality rating scale has also highlighted a starting point for future research.

\section{Future research}

This review highlights a need for research with regards to measures of SS and PA in older people. The population is ageing at an unprecedented rate and as both SS and PA are key determinants of healthy ageing, it is important to develop and validate a general SS scale specific for older adults to be used consistently across studies examining factors associated with healthy ageing. Further validation in older adults of the Sallis SS for Exercise Scale [42], and consistent future use of this scale would also simplify and strengthen cross-study comparisons. Furthermore, the use of one well-validated PA scale which allows assessment of all modes of PA to be assessed but also be analysed separately would help inform whether other domains of PA are as influenced by SS as is the lifestyle domain.

Given the lack and variation of research available investigating the role of general support for PA levels in older adults firm conclusions were not able to be made in that category. But given the value of social support for the health and wellbeing of older adults, future research specifically in this area would be warranted.

The body of evidence for SSPA and PA was greater but nearly all these studies were cross-sectional. Therefore, it is not possible to make statements about the direction of the association, higher SSPA could be associated with higher PA, but it may also be the other way around. This field of research would therefore benefit from prospective or longitudinal studies assessing associations between SSPA and PA over time. Natural experiments could also help to elucidate the prospective association, for example, by observing the impact of joining sporting clubs or community groups offering PA options for older adults on PA levels and SSPA. There would also be great benefit in performing intervention studies where social support is manipulated to examine if changes in social support result in increased physical activity levels in older adults.

\section{Conclusions and implications}

Notwithstanding the large variability in study methodologies, in general it seems SS specific to PA is an important factor assisting older adults to be physically active, especially when coming from family members. The evidence also highlights the importance of friend support for leisure time PA in older adults. In terms of general SS, there does not seem to be an association with PA, however with far fewer studies investigating this relationship, more studies are needed to either confirm or challenge this finding. Finally, the moderate 
quality loneliness studies suggest a negative association between loneliness and PA levels, especially in females.

The findings from this review suggest that PA interventions for older adults should specifically take into consideration family as important sources of SS for general PA promotion that aims to increase PA levels across a number of PA domains. Additionally, the importance of friends as sources of support for leisure time PA in older adults is highlighted here. 'Buddy' style interventions where participants are encouraged to exercise with a partner have been successful in the general population [32] and in older adults [90]. This review suggests that this type of intervention may benefit from targeting family members as buddies or to be otherwise involved in the intervention. Finally, generalised support in the lives of older adults, as well as loneliness, may also significantly influence leisure-time PA participation, especially in women. As such, the promotion of the social benefits of PA participation should be part of interventions aimed at older adults.

\section{Additional files}

Additional file 1: PubMed search strategy. (DOCX 16 kb)

Additional file 2: Further detail about PA measurement and analysis. (DOCX $13 \mathrm{~kb}$ )

\section{Abbreviations}

LTPA: Leisure time physical activity; MVPA: Moderate to vigorous physical activity; PA: Physical activity; SS: Social support; SSPA: Social support for physical activity

\section{Acknowledgements}

Not applicable.

\section{Funding}

The primary author contributing to this study (GLS) receives PhD scholarship funding from Victoria University. The other authors were funded through salaries at Victoria University.

\section{Availability of data and materials}

Not applicable.

\section{Authors' contributions}

GLS and LB conducted the literature search. GLS and GoS conducted the quality review with assistance from $L B$ and JvU. All authors contributed to the study design, interpretation of results and manuscript preparation. All authors approve the final version of this paper.

\section{Competing interests}

The authors declare that they have no competing interests.

\section{Consent for publication}

Not applicable.

Ethics approval and consent to participate

Not applicable.

\section{Publisher's Note}

Springer Nature remains neutral with regard to jurisdictional claims in published maps and institutional affiliations.

\section{Author details}

Institute of Sport, Exercise and Active Living, Victoria University, Melbourne, Australia. ${ }^{2}$ Faculty of Health, Federation University, Ballarat, Australia. ${ }^{3}$ Department of Kinesiology, Physical Activity, Sports and Health Research Group, KU Leuven - University of Leuven, B-3000 Leuven, Belgium.

Received: 27 July 2016 Accepted: 10 April 2017

Published online: 27 April 2017

\section{References}

1. World Health Organisation, US National Institute of Aging. Global Health and Ageing. Geneva: World Health Organisation; 2011.

2. Balogun JA, Akindele KA, Nihinlola JO, Marzouk DK. Age-related changes in balance performance. Disabil Rehabil. 1994;16(2):58-62.

3. Singh MAF. Exercise comes of age: rationale and recommendations for a geriatric exercise prescription. J Gerontol Ser A Biol Med Sci. 2002;57(5):M262-M82.

4. Kendig H, Browning CJ, Thomas SA, Wells Y. Health, lifestyle, and gender influences on aging well: an Australian longitudinal analysis to guide health promotion. Public Health Educ Promot. 2014;2:70.

5. World Health Organization. Active Ageing: A Policy Framework., Geneva. 2002. http://whqlibdoc.who.int/hq/2002/WHO_NMH_NPH_02.8.pdf?ua=1. Accessed 6 June 2014.

6. de Souto Barreto P. Exercise and health in frail elderly people: a review of randomized controlled trials. Eur Rev Aging Phys Act. 2009;6(2):75-87.

7. Paterson DH, Warburton DE. Review Physical activity and functional limitations in older adults: a systematic review related to Canada's Physical Activity Guidelines. Int J Behav Nutr Phy. 2010;7(38):1-22.

8. Nunan D, Mahtani KR, Roberts N, Heneghan C. Physical activity for the prevention and treatment of major chronic disease: an overview of systematic reviews. Syst Rev. 2013;2(1):56-8.

9. Reiner M, Niermann C, Jekauc D, Woll A. Long-term health benefits of physical activity-a systematic review of longitudinal studies. BMC Public Health. 2013;13(1):813.

10. Physical Activity Guidelines Advisory Committee. Physical activity guidelines advisory committee report. In: Services DoHaH, editor. Washington, DC: 2008. A1-H14.

11. Berlin JA, Colditz GA. A meta-analysis of physical activity in the prevention of coronary heart disease. Am J Epidemiol. 1990;132(4):612-28.

12. Lee $D$, Sui $X$, Ortega FB, Kim YS, Church TS, Winett RA, et al. Comparisons of leisure-time physical activity and cardiorespiratory fitness as predictors of all-cause mortality in men and women. Brit J Sport Med. 2011:45(6):504-10.

13. Campbell AJ, Robertson MC. Rethinking individual and community fall prevention strategies: a meta-regression comparing single and multifactorial interventions. Age Ageing. 2007;36(6):656-62.

14. Organisation WH. Prevalence of insufficient physical activity among adults. Global Health Observatory data repository. World Health Organisation. 2015. http://apps.who.int/gho/data/view.main.2487?lang= en. Accessed 7 Jan 2015.

15. Schoenborn C, Adams P, Peregoy J. In: Statistics NCfH, editor. Health Behaviours of Adults: United States, 2008-2010. Maryland: US Department of Health and Human Services; 2013.

16. Aging NACo. Seniors in Canada, 2006 Report Card. Ottawa: Government of Canada; 2006.

17. Australian Bureau of Statistics. Australian Health Survey: Physical Activity, 2011-2012. 2013. http://www.abs.gov.au/ausstats/abs@.nsf/Lookup/ D4495467B7F7EB01CA257BAC0015F593?opendocument. Accessed 28 May 2014.

18. Organization WH. Global recommendations on physical activity for health. 2010

19. Bandura A. Social foundations of thought and action: A social cognitive theory. Prentice-Hall, Inc; 1986

20. Bronfenbrenner U. Toward an experimental ecology of human development. Am Psychol. 1977;32(7):513.

21. McLeroy KR, Bibeau D, Steckler A, Glanz K. An ecological perspective on health promotion programs. Health Educ Behav. 1988;15(4):351-77.

22. Ajzen I. The Theory of Planned Behavior. Organ Behav Hum Dec. 1991;50(2): 179-211.

23. Rosenstock IM, Strecher VJ, Becker MH. Social learning theory and the health belief model. Health Educ Behav. 1988;15(2):175-83.

24. Fuller BG, Stewart Williams JA, Byles JE. Active living-the perception of older people with chronic conditions. Chronic Illness. 2010;6(4):294-305. 
25. McAuley E, Jerome GJ, Marquez DX, Elavsky S, Blissmer B. Exercise selfefficacy in older adults: Social, affective, and behavioral influences. Ann Behav Med. 2003;25(1):1.

26. Ayotte BJ, Margrett JA, Hicks-Patrick J. Physical activity in middle-aged and young-old adults: the roles of self-efficacy, barriers, outcome expectancies, self-regulatory behaviors and social support. J Health Psychol. 2010;15(2):173-85.

27. van Stralen MM, De Vries H, Mudde AN, Bolman C, Lechner L. Determinants of initiation and maintenance of physical activity among older adults: a literature review. Health Psychol Rev. 2009;3(2):147-207.

28. Hansen BH, Ommundsen Y, Holme I, Kolle E, Anderssen SA. Correlates of objectively measured physical activity in adults and older people: a crosssectional study of population-based sample of adults and older people living in Norway. Int J Public Health. 2014;59(2):221-30.

29. Koeneman MA, Verheijden MW, Chinapaw MJM, Hopman-Rock M Determinants of physical activity and exercise in healthy older adults: A systematic review. Int J Behav Nutr Phy. 2011:8:142

30. Kouvonen A, De Vogli R, Stafford M, Shipley MJ, Marmot MG, Cox T, et al. Social support and the likelihood of maintaining and improving levels of physical activity: the Whitehall II Study. Eur J Public Health. 2012;22(4):514-8.

31. Carlson JA, Sallis JF, Conway TL, Saelens BE, Frank LD, Kerr J, et al. Interactions between psychosocial and built environment factors in explaining older adults' physical activity. Prev Med. 2012;54(1):68-73.

32. Kahn EB, Ramsey LT, Brownson RC, Heath GW, Howze EH, Powell KE, et al. The effectiveness of interventions to increase physical activity: A systematic review. Am J Prev Med. 2002;22(4, Supplement 1):73-107.

33. Orsega-Smith EM, Payne LL, Mowen AJ, Ho C, Godbey GC. The role of social support and self-efficacy in shaping the leisure time physical activity of older adults. J Leisure Res. 2007;39(4):705.

34. Schnittger RIB, Wherton J, Prendergast D, Lawlor BA. Risk factors and mediating pathways of loneliness and social support in communitydwelling older adults. Aging \& Mental Health. 2012;16(3):335-46.

35. Valtorta N, Hanratty B. Loneliness, isolation and the health of older adults: do we need a new research agenda? J R Soc Med. 2012;105(12): 518-22.

36. Victor C, Scambler S, Bond J, Bowling A. Being alone in later life: loneliness, social isolation and living alone. Rev Clin Gerontol. 2000;10(04):407-17.

37. Engberg E, Alen M, Kukkonen-Harjula K, Peltonen JE, Tikkanen HO, Pekkarinen $\mathrm{H}$. Life events and change in leisure time physical activity: a systematic review. Sports Med. 2012;42(5):433-47.

38. Wood YR. Social support and social networks: nature and measurement. Adv Psychol Assess. 1984;6:312-53.

39. Hupcey JE. Clarifying the social support theory-research linkage. J Adv Nurs. 1998;27(6):1231-41.

40. Williams P, Barclay L, Schmied V. Defining social support in context: a necessary step in improving research, intervention, and practice. Qual Health Res. 2004;14(7):942-60.

41. World Health Organisation. Social Determinants of Health: The Solid Facts. 2nd ed. Denmark: World Health Organization; 2003.

42. Sallis JF, Grossman RM, Pinski RB, Patterson TL, Nader PR. The development of scales to measure social support for diet and exercise behaviors. Prev Med. 1987;16(6):825-36.

43. Oka R, King A, Young DR. Sources of social support as predictors of exercise adherence in women and men ages 50 to 65 years. Women's Health (Hillsdale, NJ). 1994;1(2):161-75.

44. Karavidas M, Lim N, Katsikas S. The effects of computers on older adult users. Comput Hum Behav. 2005;21:697-711.

45. Ford ES, Ahluwalia IB, Galuska DA. Social relationships and cardiovascular disease risk factors: findings from the third national health and nutrition examination survey. Prev Med. 2000;30(2):83-92.

46. Piwoński J, Piwońska A, Sygnowska E. Is level of social support associated with health behaviours modifying cardiovascular risk? Results of the WOBASZ study. Kardiol Pol. 2012;70(8):803-9

47. Haughton McNeill L, Wyrwich KW, Brownson RC, Clark EM, Kreuter MW. Individual, social environmental, and physical environmental influences on physical activity among black and white adults: a structural equation analysis. Ann Behav Med. 2006;31(1):36-44.

48. Treiber FA, Baranowski T, Braden DS, Strong WB, Levy M, Knox W. Social support for exercise: relationship to physical activity in young adults. Prev Med. 1991;20(6):737-50.
49. Eyler AA, Brownson RC, Donatelle RJ, King AC, Brown D, Sallis JF. Physical activity social support and middle- and older-aged minority women: results from a US survey. Soc Sci Med. 1999;49(6):781-9.

50. Sallis JF, Cervero RB, Ascher W, Henderson KA, Kraft MK, Kerr J. An ecological approach to creating active living communities. Annu Rev Public Health. 2006;27:297-322

51. Mendonça G, Cheng LA, Mélo EN, de Farias Júnior JC. Physical activity and social support in adolescents: a systematic review. Health Educ Res. 2014; 29(5):822-39.

52. Liberati A, Altman DG, Tetzlaff J, Mulrow C, Gøtzsche PC, loannidis JPA, et al. The PRISMA statement for reporting systematic reviews and meta-analyses of studies that evaluate health care interventions: explanation and elaboration. Ann Intern Med. 2009:151(4):W65-94.

53. Economic Do, Nations SAU. World population ageing: 1950-2050. UN; 2002

54. Terwee CB, Mokkink LB, van Poppel MNM, Chinapaw MJM, van Mechelen W, de Vet HCW. Qualitative attributes and measurement properties of physical activity questionnaires. Sports Med. 2010;40(7):525-37.

55. Martinson B, Crain A, Sherwood N, Hayes M, Pronk N, O'Connor P. Maintaining physical activity among older adults: six months outcomes of the keep active Minnesota randomized controlled trial. Prev Med. 2008;46:111-9.

56. Gyorkos TW, Tannenbaum TN, Abrahamowicz M, Oxman AD, Scott E, Millson ME, et al. An approach to the development of practice guidelines for community health interventions. Can J Public Health. 1993;85:S8-13.

57. Sallis JF, Prochaska JJ, Taylor WC. A review of correlates of physical activity of children and adolescents. Med Sci Sport Exer. 2000;32(5):963-75.

58. Luo Y, Waite LJ. Loneliness and mortality among older adults in China. J Gerontol Series B Psychol Sci Soc Sci. 2014;69(4):633-45.

59. Netz Y, Goldsmith R, Shimony T, Arnon M, Zeev A. Loneliness is associated with an increased risk of sedentary life in older Israelis. Aging Ment Health. 2013:17(1):40-7.

60. Newall NEG, Chipperfield JG, Bailis DS, Stewart TL. Consequences of loneliness on physical activity and mortality in older adults and the power of positive emotions. Health Psychol. 2013;32(8):921-4.

61. Shankar A, McMunn A, Banks J, Steptoe A. Loneliness, social isolation, and behavioral and biological health indicators in older adults. Health Psychol. 2011:30(4):377-85

62. Shiovitz-Ezra S, Litwin H. Social network type and health-related behaviors: evidence from an American national survey. Soc Sci Med. 2012;75(5):901-4.

63. Theeke LA. Sociodemographic and health-related risks for loneliness and outcome differences by loneliness status in a sample of U.S. older adults. Res Gerontol Nurs. 2010;3(2):113-25.

64. Booth ML, Owen N, Bauman A, Clavisi O, Leslie E. Social-cognitive and perceived environment influences associated with physical activity in older Australians. Prev Med. 2000;31(1):15-22.

65. Bopp M, Wilcox S, Oberrecht L, Kammermann S, McElmurray CT. Correlates of strength training in older rural African American and Caucasian women. Women Health. 2004:40(1):1-20.

66. Gellert P, Ziegelmann JP, Warner LM, Schwarzer R. Physical activity intervention in older adults: Does a participating partner make a difference? Eur J Ageing. 2011;8(3):211-9.

67. Hall KS, McAuley E. Individual, social environmental and physical environmental barriers to achieving 10000 steps per day among older women. Health Educ Res. 2010:25(3):478-88.

68. Kim Y, Kosma M. Psychosocial and environmental correlates of physical activity among Korean older adults. Res Aging. 2013;35(6):750-67.

69. Kraithaworn P, Sirapo-ngam Y, Piaseu N, Nityasuddhi D, Gretebeck KA. Factors predicting physical activity among older Thais living in low socioeconomic urban communities. Pac Rim Int J Nurs Res. 2011;15(1):39-56.

70. Lian WM, Gan GL, Pin CH, Wee S, Ye HC. Correlates of leisure-time physical activity in an elderly population in Singapore. Am J Public Health. 1999; 89(10):1578-80.

71. McAuley E, Jerome GJ, Elavsky S, Marquez DX, Ramsey SN. Predicting long-term maintenance of physical activity in older adults. Prev Med. 2003:37(2):110-8.

72. O'Brien Cousins S. Social support for exercise among elderly women in Canada. Health Promot Int. 1995;10(4):273-82

73. Oka K, Shibata A. Determinants of meeting the public health recommendations for physical activity among community-dwelling elderly Japanese. Curr Aging Sci. 2012;5(1):58-65.

74. Glass TA, Carlos F, De Leon M, Bassuk SS, Berkman LF. Social Engagement and Depressive Symptoms in Late Life. J Aging Health. 2006;18(4):604-28. 
75. Park CH, Elavsky S, Koo KM. Factors influencing physical activity in older adults. J Exerc Rehabil. 2014;10(1):45-52.

76. Sasidharan V, Payne L, Orsega-Smith E, Godbey G. Older adults' physical activity participation and perceptions of wellbeing: Examining the role of social support for leisure. Manag Leis. 2006;11(3):164-85.

77. Schuster C, Petosa R, Petosa S. Using social cognitive theory to predict intentional exercise in post-retirement adults. J Health Educ. 1995;26(1):14-24.

78. Wilcox S, Bopp M, Oberrecht L, Kammermann SK, McElmurray CT. Psychosocial and perceived environmental correlates of physical activity in rural and older african american and white women. J Gerontol Ser B Psychol Sci Soc Sci. 2003;58B(6):329-P37.

79. Yeom H-A, Fleury J. A motivational physical activity intervention for improving mobility in older Korean Americans. West J Nurs Res. 2014; 36(6):713-31.

80. Kaplan MS, Newsom JT, McFarland BH, Lu L. Demographic and psychosocial correlates of physical activity in late life. Am J Prev Med. 2001;21(4):306-12.

81. Mowen A, Orsega-Smith E, Payne L, Ainsworth B, Godbey G. The role of park proximity and social support in shaping park visitation, physical activity, and perceived health among older adults. J Phys Act Health. 2007:4(2):167-79.

82. Vance DE, Ross LA, Ball KK, Wadley VG, Rizzo M. Correlates of individual physical activities in older adults. Act Adapt Aging. 2008;31(4):1-21.

83. Potts MK, Hurwicz M-L, Goldstein MS, Berkanovic E. Social support, healthpromotive beliefs, and preventive health behaviors among the elderly. J Appl Gerontol. 1992;11(4):425-40.

84. Adams KB, Leibbrandt $\mathrm{S}$, Moon $\mathrm{H}$. A critical review of the literature on social and leisure activity and wellbeing in later life. Ageing Soc. 2011; 31(04):683-712.

85. Allender S, Cowburn G, Foster C. Understanding participation in sport and physical activity among children and adults: a review of qualitative studies Health Educ Res. 2006;21(6):826-35.

86. Caetano SC, Silva CMFP, Vettore MV. Gender differences in the association of perceived social support and social network with selfrated health status among older adults: a population-based study in Brazil. BMC Geriatr. 2013;13(1):1-14.

87. Chemaitelly H, Kanaan C, Beydoun H, Chaaya M, Kanaan M, Sibai AM. The role of gender in the association of social capital, social support, and economic security with self-rated health among older adults in deprived communities in Beirut. Qual Life Res. 2013;22(6):1371-9.

88. Brown WJ, Heesch KC, Miller YD. Life events and changing physical activity patterns in women at different life stages. Ann Behav Med. 2009;37(3):294-305.

89. Bauman A, Phongsavan P, Schoeppe S, Owen N. Physical activity measurement-a primer for health promotion. Promot Educ. 2006;13(2):92-103.

90. Neil Thomas G, Macfarlane DJ, Guo B, Cheung BM, McGhee SM, Chou $K-L$, et al. Health promotion in older Chinese: A 12-month cluster randomized controlled trial of pedometry and peer support. Med Sci Sport Exer. 2012;44:1157.

91. Lubben JE. Assessing social networks among elderly populations. Fam Community Health. 1988;11(3):42-52.

92. Sarason IG, Levine HM, Basham RB, Sarason BR. Assessing social support: the social support questionnaire. J Pers Soc Psychol. 1983;44(1):127-39.

93. Beaudet MP. Depression. Health Rep Stat Canada, Canadian Cent Health Inf. 1996:7(4):11-24. 11-2425.

94. Turvey CL, Wallace RB, Herzog R. A revised CES-D measure of depressive symptoms and a DSM-based measure of major depressive episodes in the elderly. Int Psychogeriatr. 1999;11(02):139-48.

95. Booth ML, Owen N, Bauman A, Gore CJ. Relationship between a 14-day recall measure of leisure-time physical activity and a submaximal test of physical work capacity in a population sample of Australian adults. Res Q Exerc Sport. 1996;67(2):221-7.

96. Washburn RA, McAuley E, Katula J, Mihalko SL, Boileau RA. The physical activity scale for the elderly (PASE): evidence for validity. J Clin Epidemiol. 1999;52(7):643-51.

97. Stewart AL, Mills KM, King AC, Haskell WL, Gillis D, Ritter PL. CHAMPS physical activity questionnaire for older adults: outcomes for interventions. Med Sci Sport Exer. 2001;33(7):1126-41.

98. Huy C, Schneider S. Instrument for the assessment of middle-aged and older adults' physical activity: design, eliability and application of the German-PAQ-50+. Zeitschrift Fur Gerontologie Und Geriatrie. 2008;41(3):208-16.

99. Godin G, Shephard R. A simple method to assess exercise behavior in the community. Can J Appl Sport Sci. 1985;10(3):141-6.

100. Yang JK, Lee JH, Kim YH, Hyun SK. Relationship between psychological and social variables of explaining exercise behavior in adults. Korean J Sport Sci. 2005;17:119-30.

101. Visuthipanich V, Sirapo-ngam Y, Malathum P, Kijboonchoo K, Vorapongsathorn T, Winters-Stone KM. Physical activity questionnaire development and testing among elderly community-dwelling Thais. Thai J Nurs Res. 2010;13(4):249-67.

102. Chinuntuya P. A causal model of exercise behavior of the elderly in Bangkok Metropolis. Mahidol University: Faculty of Graduate Studies ; 2001.

103. Sallis JF, Hovell MF, Hofstetter CR, Faucher P, Elder JP, Blanchard J, et al. A multivariate study of determinants of vigorous exercise in a community sample. Prev Med. 1989;18(1):20-34.

104. Washburn R, Smith K, Jette A, Janney C. Physical Activity Scale for the Elderly: administration and scoring instruction manual. Watertown: New England Research Institute; 1991.

105. Cutrona CE, Russell DW. The provisions of social relationships and adaptation to stress. Adv Pers Relat. 1987;1(1):37-67.

106. Weiss RS. The provisions of social relationships. In: Rubin Z, editor. Doing Unto Others. Englewood Cliffs: Prentice-Hall; 1974. p. 17-26.

107. Radloff LS. The CES-D scale a self-report depression scale for research in the general population. Appl Psychol Measur. 1977;1(3):385-401.

108. de Jong-Gierveld J, Kamphuls F. The development of a rasch-type loneliness scale. Appl Psychol Measur. 1985;9(3):289-99.

109. Itakura M, Oka K, Takeda N, Watanabe Y, Nakamura Y. Exercise behavior and social support for exercise among adults. Walking Res. 2003;7:151-7.

110. Washburn RA, Smith KW, Jette AM, Janney CA. The Physical Activity Scale for the Elderly (PASE): development and evaluation. J Clin Epidemiol. 1993; 46(2):153-62.

111. Hughes ME, Waite LJ, Hawkley LC, Cacioppo JT. A short scale for measuring loneliness in large surveys - Results from two population-based studies. Res Aging. 2004;26(6):655-72.

112. Sallis JF, Hovell MF. Determinants of exercise behavior. Exerc Sport Sci Rev. 1990;18(1):307-30

113. Satariano WA, McAuley E. Promoting physical activity among older adults: From ecology to the individual. Am J Prev Med. 2003;25(3, Supplement 2):184-92.

114. Bronfenbrenner U. Ecological models of human development. Readings Dev Child. 1994:2:37-43.

115. Fredrickson BL. What good are positive emotions? Rev Gen Psychol. 1998;2(3):300

116. Ajzen I, Driver BL. Application of the theory of planned behavior to leisure choice (Application de la theorie du comportement planifie au choix du loisir). J Leisure Res. 1992;24(3):207-24.

117. Bandura A. Human agency in social cognitive theory. Am Psychol. 1989; 44(9):1175.

118. The health belief model and personal health behavior. Health Education Monographs, vol 4. Slack; 1974

119. Kirscht JP. Preventive health behavior: A review of research and issues. Health Psychol. 1983;2(3):277

120. Perez A, Fleury J. Wellness motivation theory in practice. Geriatr Nurs (New York, NY). 2009;30(2 Suppl):15--20.

\section{Submit your next manuscript to BioMed Central and we will help you at every step:}

- We accept pre-submission inquiries

- Our selector tool helps you to find the most relevant journal

- We provide round the clock customer support

- Convenient online submission

- Thorough peer review

- Inclusion in PubMed and all major indexing services

- Maximum visibility for your research

Submit your manuscript at www.biomedcentral.com/submit 